\title{
Prevalence of psychiatric problems in school going adolescents (10-19 years)
}

\author{
Jaiswal C. ${ }^{1}$, Gupta J.K. ${ }^{2}$, Chaudhery G.S. ${ }^{3}$ \\ ${ }^{1}$ Dr. Chhavi Jaiswal, Assistant Professor, Department of Pediatrics, ${ }^{2}$ Dr. J.K.Gupta, Assistant Professor, Department of \\ Medicine, ${ }^{3}$ Dr. G.S. Chaudhery, Professor \& Head, Department of Paediatrics; all authors are affiliated with Rajkiya \\ Medical College, Jalaun (U.P.) India.
}

Corresponding Author: Dr. J. K. Gupta, Assistant Professor, Department of Medicine, Rajkiya Medical College, Jalaun (U.P.) India. Email: drgschaudhary@rediffmail.com

\begin{abstract}
Background: The period of adolescence is of immense importance in life of an individual. Adolescents are exceedingly vulnerable to psychiatric disorders. This study intended to explore prevalence and decoration of psychiatric problem in adolescents. Aims and Objective: The objective of this research was to study encumbrance and nature of psychiatric problems in school going adolescents in defined geographical area and their psychological correlates. Material \& Method: A school based cross sectional study was conducted in month of July-August, 2018 in north India. In this study 1025 students in age group of 10-19 years from ten schools of north India participated. Screening was done by childhood psychopathological measurement schedule (CPMS) followed by detailed evaluation by ICD-10 criteria. Statistical analysis was done by chi-square test and percentage. Result: CPMS score $\geq 10$ were observed in 289 (28.2\%) students, with more common in mid adolescence and lower socioeconomic strata, working mother, single parents. Prevalence of psychiatric problems in adolescents according to ICD-10 criteria was found to be $20.8 \%$. Conclusion: The alarming numbers of our adolescents suffer from psychiatric problems. There is need to raise public awareness about the prevalence of these often-hidden psychopathy in Indian adolescents
\end{abstract}

Keywords: Adolescents, Psychiatric problems, Prevalence

\section{Introduction}

Adolescence is an important period of person where there is transition between childhood and adulthood can be seen. In the world of psychiatry there is always emphasis to study childhood psychiatry because most adult disorders should be reframed as extension of juvenile disorder. Adolescence is defined by WHO (world health organization) as the age group of 10-19 years. In India adolescence (10-19years) constitutes 21.4 percent of the population, comprising one fifth of total population [1].

Adolescents suffer from psychosocial problems during their development. Many of these problems are of transient nature and often get unnoticed. Moreover, children may unveil these problems in one setting but not in others (e.g. home, school). Psychiatric morbidity in adolescent is greatly influenced by their environment;

Manuscript received: $20^{\text {th }}$ July 2019

Reviewed: $30^{\text {th }}$ July 2019

Author Corrected: $5^{\text {th }}$ August 2019

Accepted for Publication: $9^{\text {th }}$ August 2019 these factors were included in the study. Till date, Indian studies have reported the prevalence rate of psychiatric disorders among children ranging from 2.6 to $35.6 \%$ [1-7]. The term psychiatric problems in children covers various psychological problems such as behavioral problems, low intelligence, anxiety, conduct disorders, psychotic symptoms, and physical illness with emotional problems and somatic disorders.

Thus, clinically significant psychopathology can be defined as a disorder in one or more of the following areas i.e. overt behavior, emotional states, interpersonal relationships and cognitive functions. The abnormality must be of sufficient duration and severity to cause functional impairment [7]. Mental health of child is significantly influenced by many environmental factors and life events such as adverse family structure, parental deprivation, bereavement, urbanism, maternal depression [7]. In a particular socio-cultural context these events assume etiological significance. 


\section{Original Research Article}

Kim-Cohen et al in their follow back study from New Zealand reported that 50 percent of adult psychiatric disorder cases had onset by the age of 15 years [8]. Castello et al in their updated review of epidemiology of childhood psychiatric disorders have opined that onset before adulthood may be a characteristic of majority of adult psychiatric disorders [9].

Psychiatric problems are rising in India, but only small percent presented to OPD. Reason for this may be less awareness to psychiatric problems and stigma of society.

This field study adds actual burden of morbidity in children. Early intervention for these has the potential to substantially alter the developmental course of these adult disorders, thereby reducing the morbidity significantly.

\section{Material and Method}

Type of study: This cross sectional study was carried out at ten arbitrarily selected schools.

Duration of the study: The present study was conducted during the month of July-August, 2018 in urban and rural area of north India.

Sampling: Five urban and five rural schools were taken for study. Adolescents in the age group of 10-19 years were included which covered classes from sixth to twelfth standard. The total numbers of children in these ten schools were 4305.1025 Students were selected randomly for the study purpose.

The study was conducted in two phases. In first phase selected sample were subjected to screening method used in this study; Childhood Psychopathology Measurement Schedule (CPMS), which was developed and standardized by Malhotra et al[10], and personal information sheet consisting of questions pertaining to their socio-demographic data given same time. CPMS contained 74 questions pertaining to 8 factors i.e. intelligence with conduct problems, behavior disorders, anxiety, depression, psychotic symptoms, special symptoms, physical illness emotional problems and somatization.

Ethical clearance: Ethical clearance from the ethical committee was taken.

Each question was directed to their parent (preferably mother) regarding the child's behavior during past one year. These answers were scored on two-point scale i.e., ' 0 ' if that particular behavior is not present and ' 1 ', if present. Those children who scored 10 or more on this score were considered positive for psychopathological disorder.

Using this cut-off score, the sensitivity and specificity for detecting probable psychopathological disorders reported by authors were $82 \%$ and $87 \%$ respectively.

After taking permission of respective principals and parents of the children these CPMS and personal data sheet distributed on same day.

After completion of CPMS by parents of the children, these were collected back and analyzed. The children who scored 10 or more were assessed further and called for interview clinically.

Each child interviewed individually in presence of senior psychiatrist and was diagnosed according to International Classification of Diseases-10 (ICD-10) criteria.

Statistical analysis: SPSS 10 pack for window was used for statistical analysis. Chi square test was used for comparing groups. $\mathrm{P}$ value less than or equal to 0.05 was considered significant.

\section{Results}

Total 1025 students participated in study. Major proportion of the studied population belonged to early (10-13) and midteens (14-16) constituting 55.90\% and 38.73\% respectively. Males (61.75\%) are out number than females $(38.24 \%)$. Mostly students belong to middle to lower class. Among 1025 students, 289 students (28.2\%) scored $\geq 10$ in CPMS score. There was no substantial difference between male and female group regarding CPMS score (Table 1).

Psychiatric morbidity is more in mid adolescence, low socioeconomic group, middle child, less educated parents, working mothers and single parent. After screening 229 students, 201 students $(20.9 \%)$ were found to have psychiatric illness according to ICD-10 criteria. 60 students having CPMS $\geq 10$ did not participate in further study. From Table 2 it was observed that most of the children had sleep disorders (37 students, $18.4 \%$ ), specific isolated phobia (23 students, $11.4 \%$ ) and hyperkinetic syndrome (16 students, $7.9 \%)$. Non organic enuresis was found in 11 students (5.5\%), PICA in 


\section{Original Research Article}

14 students $(6.9 \%)$, conduct disorder in 10 students (4.9\%), tension headache in 9 students (4.5\%), migraine in 8 students $(3.9 \%)$ and learning disorder in 7 students(3.5\%).Table 2 shows specific phobia, tension headache, nonorganic sleep disorder, hyperkinetic disorder, pica, enuresis, conduct disorder, generalized anxiety found commonly in adolescents.

Table-1: Relation of socio-demographic characteristics with CPMS score.

\begin{tabular}{|c|c|c|c|c|c|}
\hline Character & CPMS $>10$ & $\%$ & $\mathrm{CPMS}<10$ & $\%$ & P value \\
\hline \multicolumn{6}{|l|}{ Sex } \\
\hline Male & 178 & 28.1 & 455 & 71.9 & \multirow{2}{*}{$\begin{array}{l}\mathrm{P}=0.94362 \\
\text { insignificant }\end{array}$} \\
\hline Female & 111 & 28.3 & 281 & 71.7 & \\
\hline \multicolumn{6}{|l|}{ Age group } \\
\hline 10-13year & 69 & 12.0 & 504 & 88.0 & \multirow{3}{*}{$\begin{array}{c}\mathrm{P} \leq 0.0001 \\
\text { Highly significant }\end{array}$} \\
\hline 14-16year & 206 & 52.0 & 191 & 48.0 & \\
\hline 17-19year & 14 & 25.5 & 25 & 45.5 & \\
\hline \multicolumn{6}{|l|}{ Socioeconomic status } \\
\hline Upper class & 15 & 24.6 & 46 & 75.4 & \multirow{3}{*}{$\begin{array}{c}\mathrm{P} \leq 0.0001 \\
\text { Highly significant }\end{array}$} \\
\hline Middle class & 140 & 20.8 & 534 & 79.2 & \\
\hline Lower class & 134 & 46.2 & 156 & 53.8 & \\
\hline \multicolumn{6}{|l|}{ Residential area } \\
\hline Urban & 163 & 27.1 & 438 & 72.9 & \multirow{2}{*}{$\begin{array}{c}\mathrm{P}=0.3631 \\
\text { Insignificant }\end{array}$} \\
\hline Rural & 126 & 29.7 & 298 & 69.3 & \\
\hline \multicolumn{6}{|l|}{ Type of family } \\
\hline Nuclear & 169 & 28.7 & 419 & 71.3 & \multirow{2}{*}{$\begin{array}{c}\mathrm{P}=0.6523 \\
\text { Insignificant }\end{array}$} \\
\hline Joint & 120 & 27.5 & 317 & 72.5 & \\
\hline \multicolumn{6}{|l|}{ Ordinal position of child } \\
\hline Eldest & 25 & 9.69 & 233 & 90.3 & \multirow{4}{*}{$\begin{array}{c}\mathrm{P} \leq 0.0001 \\
\text { Highly significant }\end{array}$} \\
\hline Middle & 197 & 53.2 & 173 & 46.8 & \\
\hline Youngest & 54 & 15.5 & 294 & 84.5 & \\
\hline One child & 13 & 26.5 & 36 & 73.5 & \\
\hline \multicolumn{6}{|l|}{ Condition of mother } \\
\hline Expire & 9 & 64.3 & 5 & 35.7 & \multirow{2}{*}{$\begin{array}{l}\mathrm{P}=0.0025 \\
\text { Significant }\end{array}$} \\
\hline Alive & 280 & 27.7 & 731 & 72.3 & \\
\hline \multicolumn{6}{|l|}{ Condition of father } \\
\hline Expire & 17 & 53.1 & 15 & 46.9 & \multirow{2}{*}{$\begin{array}{l}\mathrm{P}=0.0014 \\
\text { Significant }\end{array}$} \\
\hline Alive & 272 & 27.4 & 721 & 72.6 & \\
\hline \multicolumn{6}{|l|}{ Mother's occupation } \\
\hline Housewife & 235 & 27.2 & 630 & 72.8 & \multirow{6}{*}{$\begin{array}{c}\mathrm{P}=0.001637 \\
\text { Significant }\end{array}$} \\
\hline Laborer & 12 & 26.1 & 34 & 73.9 & \\
\hline Farmer & 15 & 28.3 & 38 & 71.7 & \\
\hline Business & 5 & 20.0 & 20 & 80.0 & \\
\hline $\begin{array}{l}\text { Teacher, Engineer, Lawyer, } \\
\text { and other private job }\end{array}$ & 13 & 59.1 & 9 & 40.9 & \\
\hline Expire & 9 & 64.3 & 5 & 35.7 & \\
\hline
\end{tabular}


Table-2: Prevalence of specific disorder according to ICD-10 criteria

\begin{tabular}{|c|c|c|c|c|c|c|}
\hline \multirow[t]{2}{*}{ Disorders } & \multicolumn{2}{|c|}{ Male } & \multicolumn{2}{|c|}{ Female } & \multicolumn{2}{|c|}{ Total } \\
\hline & No. & $\%$ & No. & $\%$ & No. & $\%$ \\
\hline Hyperkinetic syndrome & 11 & 10.5 & 5 & 5.15 & 16 & 7.96 \\
\hline Conduct disorder & 7 & 6.73 & 3 & 3.09 & 10 & 4.97 \\
\hline Oppositional defiant disorder & 2 & 1.92 & 1 & 1.03 & 3 & 1.49 \\
\hline Non organic enuresis & 7 & 6.73 & 4 & 4.12 & 11 & 5.47 \\
\hline Non organic encopresis & 1 & 0.96 & 0 & 0.00 & 1 & 0.49 \\
\hline PICA & 8 & 7.69 & 6 & 6.18 & 14 & 6.96 \\
\hline Behavior disorder NOS & 3 & 2.88 & 2 & 2.06 & 5 & 2.48 \\
\hline Chronic motor/ vocal tic disorder & 2 & 1.92 & 0 & 0.00 & 2 & 0.99 \\
\hline Transient tic disorder & 1 & 0.96 & 1 & 1.03 & 2 & 0.99 \\
\hline Communication disorder & 1 & 0.96 & 1 & 1.03 & 2 & 0.99 \\
\hline Depressive episode & 2 & 1.92 & 4 & 4.12 & 6 & 2.98 \\
\hline Dysthymia & 2 & 1.92 & 3 & 3.09 & 5 & 2.48 \\
\hline Mental retardation & 4 & 3.84 & 2 & 2.06 & 6 & 2.98 \\
\hline Sleep walking & 0 & 0.00 & 1 & 1.03 & 1 & 0.49 \\
\hline Sleep terror & 2 & 1.92 & 5 & 5.15 & 7 & 3.48 \\
\hline Night mare & 2 & 1.92 & 5 & 5.15 & 6 & 3.48 \\
\hline Sleep wake disorder & 15 & 14.4 & 8 & 8.24 & 23 & 11.44 \\
\hline Social phobia & 3 & 2.88 & 2 & 2.06 & 5 & 2.48 \\
\hline Specific isolated phobia & 8 & 7.69 & 15 & 15.46 & 23 & 11.44 \\
\hline Generalized anxiety disorder & 2 & 1.92 & 5 & 5.15 & 6 & 3.48 \\
\hline Panic disorder & 1 & 0.96 & 2 & 2.06 & 3 & 1.49 \\
\hline Stuttering & 3 & 2.88 & 2 & 2.06 & 5 & 2.48 \\
\hline Migraine & 3 & 2.88 & 5 & 5.15 & 8 & 3.98 \\
\hline Tension headache & 8 & 7.69 & 11 & 11.34 & 9 & 4.50 \\
\hline Learning disorder & 5 & 4.80 & 2 & 2.06 & 7 & 3.48 \\
\hline Somatoform disorder & 1 & 0.96 & 2 & 2.06 & 3 & 1.49 \\
\hline Total & 104 & 100.0 & 97 & 100 & 201 & 100 \\
\hline
\end{tabular}

\section{Discussion}

In the present study $28.2 \%$ (289 out of 1025 ) adolescent students of age 10-19 years had CPMS score $\geq 10$ where as Bansal and Barman [6] in 10-15year group showed $31.7 \%$, Rahi et al[11] in 4-14 year group showed $16.5 \%$. After second stage evaluation with ICD-10, overall prevalence was found $20.9 \%$, similar to result of study conducted by WHO in four developing countries (1981) including India, showed prevalence of 20\% [12]. A study by Indian Council of Medical Research (ICMR) in 2001 showed prevalence to be $13.4 \%$ in the age group 0-16 years [13]. Study from Bangalore revealed the prevalence rate of $12.5 \%$ in community [14], 39.6\% in community based sample from Amritsar [15], 9.4\% in 8-12 year olds from a community sample in Kerala [6], 16.8\% in 10-19 year olds from a community sample in Faridkot [2], and 6.3\% in 4-11 year old school children in Chandigarh [16]. In recent years, there have been several population studies giving fairly reasonable estimate of the prevalence of child and adolescents mental disorder (CAMD) in low and middle 


\section{Original Research Article}

income countries. Overall rates of childhood and adolescents mental disorders (CAMD) in India and other middle and low income countries are 6-15\% which is on lower side as compared to reported rates from certain western countries such as $18.1 \%$ in Canada [17], 20.7\% in Germany [18], 22.5\% in Switzerland [19] and $21 \%$ in USA [20]. In present study no gender based preponderance found as many other studies showed male preponderance [2] [13, 21, 22].

Out of 289 students, the age group of 14-16 year had more number of suffering adolescents followed by age group 17-19 year. There may be various factors operating for this result like increasing burden of studies, emotional disturbances, and parent's perception of abnormal behavior. Other studies with similar results were also reported [7, 15], but Rahi et al found psychopathy more commonly in the age group of 7-10 year [11]. Higher prevalence of problems in lower socioeconomic families observed in current study is similar with various other studies [3, 6, 11, 23]. The increased risk is because the factors like malnutrition, illiteracy, and negligence in the childcare are associated with lower socio-economic status.

The percentage of children with no problem showed no significant difference in term of distribution of family structure. It corroborates with the findings of [3, 6, 7], whereas other studies found more cases in nuclear families [2, 5, 22]. Present work suggest that majority of the children with illness came from middle birth order while studies by Offord [17], Anita et al [4], Rahi et al[11 and Kaur S et al[2] showed that majority of the ill children were first born. There was no urban and rural difference found in present study. This might be because the economic status of the population registered in the schools of both the areas was more or less similar. Parent's education level affect child upbringing so psychiatric morbidity is more prevalent in less educated parents. Rahi et al[11] study also showed psychopathological problems highest in off spring of illiterate mothers.

Present study reveal psychiatric morbidity were more in job doing mothers, while Rahi et al[11] showed no association with mother's occupation status. Parent expiry had drastic effect on children, so psychiatry problems were more prevalent in those students whose mother or father expired. Among different disorders, most of the children had sleep disorders (18.4\%), specific isolated phobia (11.4\%) and hyperkinetic disorder (7.9\%). Bansal and Barman [7] found prevalent psychiatric disorders to be specific isolated phobia $(19.6 \%)$, other non-organic sleep disorder (12\%) and tension headache $(11.5 \%)$. Deivasinagamini [3] found prevalent psychiatric disorders to be conduct disorder $(14.3 \%)$, enuresis $(14.3 \%)$, mental retardation $(2.9 \%)$ and hyperkinetic disorder $(1.7 \%)$. In the present study, conduct disorder was found in $4.9 \%$ of students, pica found in $6.9 \%$, enuresis in $5.5 \%$, tension headache in $4.5 \%$, and mental retardation in $2.9 \%$ of the students. An another study in 4-16 year age group children by Srinath et al[14] was preceded by enuresis (6.2\%) followed by specific phobia $(2.9 \%)$, hyperkinetic disorder (1.6\%) and stuttering (1.5\%).

Limitations: The study has been done in a small number of children where male children are significantly higher in number than female. Cross sectional study should be followed by longitudinal study to find out the course and pattern of their disorder. Moreover, other socio-demographic entities should be searched for and compared to find out any possible correlation.

\section{Conclusion}

In the inference of my work on this topic, it is imperative to say that this type of epidemiological studies are very necessary to carry out on large scale time to time and follow up them longitudinally for better understanding of childhood problems and their adult counterpart. Many of these problems are transient in nature, so longitudinal follow up is very necessary. The results of study have insinuation for clinical training, practice and policy initiatives. As pediatrician, authors were the first to come in contact of these children. Hence, these problems should be understood with depth, and counsel them accordingly. So, to reduce some burden of psychiatric problems from our societies which are increasing day by day.

\section{What the study adds in the existing knowledge?}

This is first study from the region of Bundelkhand. No previous study provides any data from our region about psychiatric morbidity in adolescent children. In the first study 201 students $(20.9 \%)$ were found to have psychiatric illness according to ICD-10 criteria, which was higher than other studies. This study included factors such as mother expiry or father expiry and type of mother's occupation as demographic factors. It was found significant correlation with child's psychiatric morbidity. 


\section{Author's contribution:}

This study was designed by Dr. Chhavi Jaiswal and Dr. G.S Chaudhery. First phase data collection and analysis was done by Dr. J.K Gupta and Dr. Chhavi Jaiswal. Second phase interview done in presence of all three authors. Data analysis was done by Dr. Chhavi Jaiswal. Manuscript prepared by Dr. Chhavi and Dr. J.K. Gupta

Funding: Nil, Conflict of interest: None initiated, Permission from IRB: Yes

\section{References}

1. Ahmad A, Khalique N, Khan Z, Amir A. Prevalence of psychosocial problems among school going male adolescents. Indian J Comm Med. 2007; 32(3):219. doi: 10.4103/0970-0218.06836

2. Kaur S, Thapar SK, Shandilya V. The Prevalence of Psychiatric morbidity among school children. Int J Med Dent Sci. 2015;4(2):834-841.

3. Deivasigamani TR. Psychiatric morbidity in primary school children-an epidemiological study. Indian $\mathbf{J}$ Psych. 1990;32(3):235.

4.Gaur DR, Vohra AK, Subash S, Khurana H. Prevalence of psychiatric morbidity among 6 to 14 years old children. Indian J Comm Med. 2003;28 (03): 133-137.

5. Hackett R, Hackett L, Bhakta P, Gowers S. The prevalence and associations of psychiatric disorder in children in Kerala, South India. The Journal of Child Psychology and Psychiatry and Allied Disciplines. 1999; 40(5):801-7.

6. Lal N, Sethi BB. Estimate of mental ill health in children of an urban community. Indian J Pediatr. 1977; 44(350):55-64. doi:10.1007/bf02753627.

7. Bansal PD, Barman R. Psychopathology of school going children in the age group of 10-15 years. Int $\mathrm{J}$ Appl Basic Med Res. 2011; 1(1): 43-7. doi: 10.4103/ 2229-516X.81980.

8. Kim-Cohen J, Caspi A, Moffitt TE, Harrington H, Milne BJ, Poulton R. Prior juvenile diagnoses in adults with mental disorder: developmental follow-back of a prospective-longitudinal cohort. Arch Gen Psychiatry. 2003; 60(7):709-17.doi:10. 1001/ archpsyc. 60.7.709
9. Costello EJ, Foley DL, Angold A. 10-year research update review: the epidemiology of child and adolescent psychiatric disorders: II. Developmental epidemiology. J Am Acad Child \& Adoles Psych. 2006; 45 (1): 8-25.doi: https: //doi.org/ 10.1097/01. chi. 0000 1849 29.41423.c0

10. Malhotra S, Varma VK, Verma SK, Malhotra A. Childhood psychopathology meausrement schedule: development and standardization. Indian J Psych. 1988; 30 (4):325.

11. Rahi M, Kumavat AP, Garg S, Singh M. Sociodemographic correlates of psychiatric disorders. Indian J Pediatr. 2005;729(5):395-398. doi:http://doi.org/10. 1007 /BF02731734

12.GielR, de ArangoMV, Climent CE, HardingTW, Ibra-him HH, Ladrido-Ignacio L, et al. Childhood mental disorders in primary health care: results of observations in four developing countries. A report from the WHO collaborative Study on Strategies for Extending Mental Health Care. Pediatrics. 1981; 68 (5): 677- 83 .

13. Indian Council of Medical Research. Epidemiological study of child and adolescent psychiatric disorders in urban and ruralareas. ICMR Bull. 2001; 3: $54-5$.

14. Srinath S, Girimaji SC, Gururaj G, Seshadri S, Subbakrishna DK, Bhola P, et al. Epidemiological study of child \& adolescent psychiatric disorders in urban \& rural areas of Bangalore, India. Indian $\mathrm{J}$ Med Res. 2005;122(1):67-79.

15. Chhabra GS, Sodhi MK. Factors contributing to psycho-social Ill-health in male adolescents. Online $\mathbf{J}$ Health Allied Sci. 2011;10(3):1-4.

16. Malhotra S, Kohli A, Arun P. Prevalence of psychiatric disorders in school children in India. Indian J Med Res. 2002;116:21-28.

17. Offord DR, Boyle MH, Szatmari P, Rae-Grant NI, Links PS, Cadman DT, Byles JA, Crawford JW, Blum HM, Byrne C, Thomas H. Ontario Child Health Study: II. Six-month prevalence of disorder and rates of service utilization. Arch Gen Psych. 1987; 44(9): 832-6. 
18. Weyerer S, Castell R, Biener A, Artner K, Dilling $\mathrm{H}$. Prevalence and treatment of psychiatric disorders in 3 to 14-year-old children: results of a representative field study in the small town rural region of Traunstein, upper Bavaria. Acta Psychiatr Scand.1988;77(3):290-6. doi: https://doi. org/10. 1111/j. 1600-0447. 1988.tb 05123. $\mathrm{x}$

19. Steinhausen HC, Metzke CW, Meier M, Kannenberg R. Prevalence of child and adolescent disorders: The Zurich Epidemiological Study. Acta Psychiatr Scand.1998; 98:262-271. doi: https://doi.org/ 10.1111 /j. 1600 -0447.1998.tb10082.x

20. United States Department of Health and Human Services. Mental Health: A Report of the Surgeon General. Rockville, MD, United States Department of health and Human Services, Substance Abuse and Mental Health Service Administration, Centre for Mental Health Services, National Institutes of Health, National Institute of Mental Health. 1999

21. Banerjee T. Psychiatric morbidity among rural primary school children in West Bengal. Indian J Psych. 1997; 39(2):130-135.

22. Verghese A, Beig A. Psychiatric disturbance in children-an epidemiological study. Indian J Med Res. 1974; 62(10):1538-42.

23. Shenoy J, Kapur M. Prevalence of scholastic backwardness among five to eight year old children. Indian J Psych. 1996;38(4):201-7.

\section{How to cite this article?}

Jaiswal C, Gupta J.K, Chaudhery G.S. Prevalence of psychiatric problems in school going adolescents (10-19 years). Int J Pediatr Res. 2019; 6(08):381-387.doi:10. 17511/ijpr.2019.i08.01 